Тищенко В. Н., доктор сельскохозяйственных наук, профессор,

Панченко П. М., аспирант *,

Чернышева О. П., аспирант *

Полтавская государственная аграрная академия

\title{
ИДЕНТИФИКАЦИЯ СОРТОВ И СЕЛЕКЦИОННЫХ ЛИНИЙ ПШЕНИЦЫ ОЗИМОЙ ПО СБАЛАНСИРОВАННОСТИ КОЛИЧЕСТВЕННЫХ ПРИЗНАКОВ С ИСПОЛЬЗОВАНИЕМ КЛАСТЕРНОГО АНАЛИЗА
}

\section{Рецензент - доктор сельскохозяйственных наук, профессор В. Д. Мединец}

\begin{abstract}
Ідентифікація сортів та селекиійних ліній пшениці озимої в кластерному аналізі дала змогу виділити генотипи, в яких Евклідова відстань між кількісними ознаками є мінімальною. До того ж вони демонструють високий рівень збалансованості основних генеративних, вететативних ознак та урожайності. Використання кластерного аналізу

для ідентифікаиї̈ генотипів наближає нас до створення теоретичної і практичної моделі сорту пшениці озимої, в якого сприятливе співвідношення кількісних та якісних ознак дає можливість протистояти негативним впливам навколишнього середовища та формувати високу продуктивність.
\end{abstract}

Ключевые слова: кластерный анализ, группируюшие признаки, индивидуальный отбор, селекичонный процесс, группь кластеров, сбалансированные генотипы.

Постановка проблемы. В процессе эволюции растительных объектов среда создала виды, которые имеют идеальную сбалансированность признаков, и это обеспечивает им выживание в постоянно изменяющихся климатических условиях. Сорта пшеницы озимой - растительные объекты, созданные человеком за очень короткий промежуток времени, и, безусловно, гибридизация не дает идеальной сбалансированности признаков в генотипе, как это делала природа на протяжении продолжительного периода времени. Стремление селекционера улучшить методом подбора родительских пар и скрещиванием главные признаки пшеницы озимой не обеспечивает необходимой сбалансированности количественных признаков. Благоприятное соотношение в организме количественных и качественных признаков дает колоссальные возможности любому биологическому объекту, в т. ч. и сортам пшеницы озимой гибридного происхождения, противостоять среде и формировать высокую продуктивность.
Анализ последних исследований и публикаций по данной проблеме. В селекционном центре Полтавской государственной аграрной академии на протяжении 15-летнего периода ведутся исследования, направленные на поиски математических методов, позволяющих оценить уровень сбалансированности основных количественных признаков у сортов и селекционных линий пшеницы озимой. В основу исследований взят кластерный анализ с использованием в качестве группирующих признака масса стебля $\left(\mathrm{M}_{5}\right)$ и индекса линейной плотности колоса (ИЛПК - отношение количества зерен в колосе к длине колоса) $[1,3]$.

Следует отметить, что кластерный анализ был использован в селекционном процессе по пшенице озимой для:

- распределения гибридных растений $\mathrm{F}_{2}$ в отдельные группы кластеров и отбора для дальнейшей работы элитных растений из групп кластеров, включающих признаки и индексы, имеющие наиболее тесные корреляционные связи с продуктивностью;

- характеристики селекционных линий пшеницы озимой по хозяйственно полезным признакам (ХПП) и адаптивным свойствам, а также отбора высокопродуктивных генотипов на начальных этапах селекции $\left(\mathrm{F}_{4}-\mathrm{F}_{6}\right)$; проведения рекуррентных индивидуальных отборов внутри частично гомозиготизированных селекционных линий $\mathrm{F}_{4}-\mathrm{F}_{6}$;

- в первичных звеньях при проведении семеноводства уже созданных сортов пшеницы озимой $[1,2]$.

Однако исследований, изучающих уровень сбалансированности основных количественных признаков у сортов и селекционных линий пшеницы озимой, в доступных источниках не обнаружено.

\footnotetext{
* Научный руководитель - доктор сельскохозяйственных наук, профессор В. Н. Тищенко
} 
Цель исследований - установить на основе экспериментальных данных возможность использования кластерного анализа для оценки сортов и селекционных линий пшеницы озимой по сбалансированности основных количественных признаков и урожайности.

Задачи исследований: на основе математического метода - кластерного анализа - попытаться найти пути использования этого метода для идентификации сортов пшеницы озимой различного географического происхождения и селекционного материала по сбалансированности количественных признаков, как таковых, которые определяют адаптивные свойства и потенциал урожая с единицы площади.

Таким образом, используя огромные выборки генотипов и их структурных элементов, анализируя соотношение их уровня с помощью Эвклидовой метрики, классифицировали сорта пшеницы озимой и выявили степень сбалансированности основных составляющих урожая.

Материал и методика исследований. В качестве материала для исследований были взяты в СП-1 175, а в СП-2 - 167 сортов и селекционных линий, высеянные в два срока посева с разницей в 30 дней в 2009 году.

В кластерном анализе в основу группировок по всему массиву (но отдельно по каждому сроку посева) были взяты количественные признаки - масса воздушносухого стебля в г $\left(\mathrm{M}_{5}\right)$ и линейная плотность колоса (ЛПК), вычисляемая по отношению количества зерен в колосе (КЗ) к длине колоса (ДК). Параллельно с основными группирующими признаками $\left(\mathrm{M}_{5}\right.$, ЛПК) в анализ были включены признаки генеративной части растения - масса зерна с колоса, г $\left(\mathrm{M}_{1}\right)$; число зерен в колосе, шт. (ЧЗ); масса колоса с семенами, г $\left(\mathrm{M}_{3}\right)$; масса 1000 зерен, г (МТ3); количество колосков в колосе, шт. (КК); вегетативной части растения - высота растения, см (Н); длина колосонесущего междоузлия, см (ДВМ); длина колоса, см (ДК); масса растения, г $\left(\mathrm{M}_{2}\right)$; масса половы колоса, г $\left(\mathrm{M}_{4}\right)$ и индексы: уборочный $(\mathrm{HI})$ - отношение массы зерна к массе растения, аттракции (AI) - отношение массы колоса к массе стебля, индекс продуктивного потенциала колоса (IPP) - отношение массы зерна к массе колоса. Кроме того в анализ включалась урожайность зерна, ц/га (УЗ) по каждому сорту и селекционной линии (СЛ).

Кластерный анализ выполнялся в модуле Cluster Analysis пакета программ STATISTICA. При построении дендрограмм использовалась Эвклидова метрика и метод единичной связи.

\section{Результаты исследований.}

Анализ кластеров СП-1. В 2009 году в СП-1 анализируемые сорта и СЛ (175) были распределены в шести кластерах. Самая удачная группировка отмечена в шестом кластере (6-я группа), где сконцентрировалось 28 сортов и СЛ. В эту группу вошли самые продуктивные генотипы, лимит варьирования которых по урожайности находился в пределах от 50,0 ц/га до 94,7 ц/га.

Нами отмечены случаи, когда в лучшую группу кластера не попадали самые урожайные генотипы или сорта. Объясняется это тем, что у них некоторые из генеративных признаков имели невысокое значение по отношению к среднему значению группы по этому признаку, т. е. сорта или СЛ не были сбалансированы по основным признакам генеративной части растения. Например, в третьей группе 6-го кластера сконцентрировались сорта, у которых урожайность была очень высокой - на уровне 89,4 ц/га, однако уровень формирования некоторых количественных признаков у них был меньше, чем у сортов лучшей группы 6-го кластера. По-видимому, формы с высоким уровнем урожайности, но низкими значениями отдельных генеративных признаков не включались в лучшие группы кластеров. Учитывая, что урожайность сортов пшеницы озимой обусловлена особенностями составляющих ее компонентов, которые модифицируются под влиянием факторов окружающей среды [3], можно сделать вывод, что снижение величины одного из результирующих факторов урожайности в дальнейшем будет определять уровень адаптивности испытываемых сортов и СЛ.

Рассматривая уровень группировки других генеративных признаков $-\mathrm{M}_{1}, \mathrm{M}_{3}$, ЧЗ, МТЗ - видим, что в лучшей группе 6-го кластера (табл.1) эти признаки имели самые высокие значения по лимитам варьирования из всех 175 анализируемых сортов и селекционных линий. Так, генотипы с уровнем формирования массы зерна с колоса $\left(\mathrm{M}_{1}\right)$ имели самое высокое значение в опыте 3,2 г; массы колоса с семенами $\left(\mathrm{M}_{3}\right)-4,3$; числа зерен (ЧЗ) - 72,8, массы 1000 зерен (МТ3) - 51,5, количество колосков в колосе (КК) - 22,6. По сути дела, мы можем смело утверждать, что идентификация генотипов в кластерном анализе приближает нас к созданию теоретической и практической модели сорта пшеницы озимой, идеальной по сбалансированности по основным количественным признакам.

Возьмем, к примеру, сорт пшеницы озимой иностранной селекции GkVevesky UA0105944 (табл. 2), урожайность которого в СП-1 состави- 
ла 89,4 ц/га, однако он не был идентифицирован в лучшую группу 6-го кластера, на наш взгляд, по трем основным причинам: во-первых, он имел низкий уровень формирования массы колоса с семенами $\left(\mathrm{M}_{3}\right)-2,3$ г (при среднем значении в лучшей группе кластера равном 3,5 г); вовторых, число зерен было недостаточно высоким - 52,4 (при среднем значении в лучшей группе кластера, равном 60,2); в-третьих, было отмече- но низкое значение массы стебля - 1,3 г (при среднем значении в лучшей группе кластера равном 1,9 г). Три вышеуказанные составляющие - Ч3, $\mathrm{M}_{3}, \mathrm{M}_{5}$ - не были сбалансированы в анализируемом сорте, а они, по-видимому, и определяют уровень адаптивного потенциала данного сорта в СП-1 и СП-2. Поэтому данный сорт не был включен в лучшую группу 6-го кластера.

\section{1. Распределение сортов и селекционных линий пиеницы озимой по группам 6-го кластера} (генеративные признаки), 2009 2., СП-1

\begin{tabular}{|c|c|c|c|c|c|c|c|c|}
\hline \multicolumn{2}{|c|}{ Кластеры } & Число линий & УK & $\mathrm{M}_{1}$ & $\mathrm{M}_{3}$ & 43 & MT3 & KK \\
\hline \multirow{12}{*}{$\mathrm{K}_{6}$} & \multirow[b]{2}{*}{ I } & 30 & $42,2 \pm 18,7$ & $2,4 \pm 0,2$ & $3,2 \pm 0,3$ & $53,4 \pm 5,5$ & $44,8 \pm 4,0$ & $19,7 \pm 1,0$ \\
\hline & & LV & $5,0-67,5$ & $1,9-2,7$ & $2,6-3,7$ & $45,6-70,2$ & $37,6-52,2$ & $18,2-22,0$ \\
\hline & \multirow{2}{*}{ II } & 18 & $52,7 \pm 12,9$ & $2,7 \pm 0,3$ & $3,5 \pm 0,4$ & $60,2 \pm 4,8$ & $44,6 \pm 3,1$ & $20,6 \pm 1,2$ \\
\hline & & LV & $36,3-85,0$ & $2,3-3,2$ & $3,1-4,3$ & $54,4-72,8$ & $37,1-50,3$ & $18,2-22,6$ \\
\hline & \multirow{2}{*}{ III } & 38 & $47,2 \pm 15,1$ & $2,3 \pm 0,2$ & $3,0 \pm 0,3$ & $51,3 \pm 5,0$ & $45,1 \pm 3,0$ & $19,4 \pm 1,0$ \\
\hline & & LV & $15,0-89,4$ & $1,9-2,8$ & $2,6-3,6$ & $44,5-68,3$ & $38,1-51,5$ & $17,4-22,0$ \\
\hline & \multirow{2}{*}{ IV } & 22 & $41,4 \pm 18,3$ & $2,0 \pm 0,3$ & $2,6 \pm 0,4$ & $45,1 \pm 6,1$ & $44,0 \pm 4,3$ & $18,9 \pm 1,4$ \\
\hline & & LV & $16,3-85,0$ & $1,3-2,8$ & $1,7-3,6$ & $32,6-57,7$ & $35,8-53,4$ & $16,1-21,2$ \\
\hline & \multirow{2}{*}{ V } & 26 & $45,3 \pm 14,8$ & $2,5 \pm 0,2$ & $3,2 \pm 0,3$ & $58,0 \pm 4,7$ & $43,1 \pm 2,6$ & $20,1 \pm 0,9$ \\
\hline & & $\mathrm{LV}$ & $16,3-76,3$ & $2,0-3,0$ & $2,7-3,8$ & $51,1-71,0$ & $37,3-46,7$ & $18,4-21,8$ \\
\hline & \multirow{2}{*}{ VI } & 13 & $46,9 \pm 19,4$ & $2,4 \pm 0,2$ & $3,2 \pm 0,3$ & $53,4 \pm 5,5$ & $44,8 \pm 4,0$ & $19,7 \pm 1,0$ \\
\hline & & LV & $15,0-76,3$ & $1,9-2,7$ & $2,6-3,7$ & $45,6-70,2$ & $37,6-52,2$ & $18,2-22,0$ \\
\hline
\end{tabular}

2. Урожсайность и уровень формирования основных количественных признаков сорта пшеницы озимой GkVevesky

\begin{tabular}{|c|c|c|c|}
\hline Признаки, индекс & СП-1 & СП-2 & ЛГ \\
\hline $\mathrm{y}$ & 89,4 & 68,8 & 52,7 \\
\hline $\mathrm{M}_{1}$ & 2,9 & 2,8 & 2,7 \\
\hline $\mathrm{M}_{3}$ & 2,3 & 2,2 & 3,5 \\
\hline $\mathrm{M}$ & 52,4 & 49,7 & 60,2 \\
\hline $\mathrm{MT3}_{5}$ & 43,3 & 45,1 & 44,6 \\
\hline ИЛПК & 1,28 & 1,37 & 1,9 \\
\hline
\end{tabular}

3. Распределение сортов и селекционных линий пиеницы озимой

по группам 6-го кластера (вегетативные признаки), 2009 г., СП-1

\begin{tabular}{|c|c|c|c|c|c|c|c|c|c|}
\hline \multicolumn{2}{|c|}{$\begin{array}{c}\text { Клас- } \\
\text { теры }\end{array}$} & $\begin{array}{l}\text { Число } \\
\text { линий }\end{array}$ & УК & $\mathrm{H}$ & ДВМ & ДК & $\mathrm{M}_{2}$ & $\mathrm{M}_{5}$ & $\mathrm{M}_{4}$ \\
\hline & I & 30 & $42,2 \pm 18,7$ & $85,4 \pm 7,5$ & $32,7 \pm 5,0$ & $9,4 \pm 1,0$ & $4,9 \pm 0,3$ & $1,7 \pm 0,1$ & $0,8 \pm 0,1$ \\
\hline & 1 & $\mathrm{LV}$ & $5,0-67,5$ & $72,8-101,9$ & $22,5-45,6$ & $7,6-12,1$ & $4,3-5,3$ & $1,5-2,0$ & $0,6-1,0$ \\
\hline \multirow{10}{*}{$\mathrm{K}_{6}$} & \multirow{2}{*}{ II } & 18 & $52,7 \pm 12,9$ & $83,7 \pm 6,7$ & $33,1 \pm 3,9$ & $9,1 \pm 0,9$ & $5,4 \pm 0,5$ & $1,9 \pm 0,2$ & $0,8 \pm 0,1$ \\
\hline & & LV & $36,3-85,0$ & $73,6-97,3$ & $27,0-40,3$ & $7,7-10,4$ & $4,8-6,9$ & $1,7-2,6$ & $0,7-1,1$ \\
\hline & \multirow{2}{*}{ III } & 38 & $47,2 \pm 15,1$ & $76,4 \pm 5,2$ & $29,2 \pm 3,4$ & $8,5 \pm 0,8$ & $4,5 \pm 0,3$ & $1,4 \pm 0,1$ & $0,7 \pm 0,1$ \\
\hline & & $\mathrm{LV}$ & $15,0-89,4$ & $64,5-85,5$ & $20,9-35,8$ & $7,4-11,3$ & $4,0-5,2$ & $1,2-1,6$ & $0,5-1,1$ \\
\hline & \multirow{2}{*}{ IV } & 22 & $41,4 \pm 18,3$ & $78,3 \pm 7,1$ & $29,8 \pm 3,5$ & $8,7 \pm 1,0$ & $4,0 \pm 0,5$ & $1,4 \pm 0,2$ & $0,7 \pm 0,1$ \\
\hline & & $\mathrm{LV}$ & $16,3-85,0$ & $64,3-89,5$ & $24,5-37,7$ & $6,9-10,4$ & $2,5-5,0$ & $0,8-1,6$ & $0,4-0,8$ \\
\hline & \multirow{2}{*}{ V } & 26 & $46,9 \pm 19,4$ & $69,6 \pm 3,3$ & $26,9 \pm 3,8$ & $7,7 \pm 0,8$ & $3,7 \pm 0,4$ & $1,1 \pm 0,1$ & $0,6 \pm 0,1$ \\
\hline & & LV & $15,0-76,3$ & $64,6-77,2$ & $21,1-34,1$ & $6,8-8,9$ & $3,0-4,4$ & $1,0-1,2$ & $0,4-0,7$ \\
\hline & \multirow{2}{*}{ VI } & 13 & $46,9 \pm 19,4$ & $85,4 \pm 7,5$ & $32,7 \pm 5,0$ & $9,4 \pm 1,0$ & $4,9 \pm 0,3$ & $1,7 \pm 0,1$ & $0,8 \pm 0,1$ \\
\hline & & $\mathrm{LV}$ & $15,0-76,3$ & $72,8-101,9$ & $22,5-45,6$ & $7,6-12,1$ & $4,3-5,3$ & $1,5-2,0$ & $0,6-1,0$ \\
\hline
\end{tabular}


По лучшей группе 6-го кластера (СП-1) 18 генотипов (табл. 3) группировали вегетативные признаки следующим образом: масса стебля по второй, лучшей группе, была отмечена на уровне $\bar{x}=1,9 \pm 0,2$ г с лимитом варьирования (LV) 1,7-2,6 г, высота растения (Н) составляла $\bar{x}=83,7 \pm 6,7 \mathrm{~cm}$, длина колоса (ДК) $-\bar{x}=9,1 \pm 0,9$ см и масса растения $\left(\mathrm{M}_{2}\right) \bar{x}=5,4 \pm 0,5$ г.

Следует отметить, что в лучшую группу кластера сгруппировались сорта, имеющие самое высокое значение по массе растения. Это раскрывает закономерности формирования продуктивности генотипов: самое высокое значение по массе растения отмечается одновременно с наличием мощного колоса $(\bar{x}=3,5 \pm 0,4$ г), высоким значением массы зерна с колоса $(\bar{x}=2,7 \pm 0,3$ г), самым большим значением признаков количество зерен $(\bar{x}=60,2 \pm 4,8$ г) и масса 1000 зерен $(\bar{x}=44,6 \pm 3,1$ г), т. е. кластерный анализ группирует сбалансированные генотипы не только по признакам генеративной части растения, но и по вегетативным признакам.

Анализ распределения сортов и СЛ пшеницы озимой по селекционным индексам (табл. 4) показал, что в лучшей второй группе 6-го кластера идентифицировались сорта, у которых были достаточно высокие показатели по уборочному индексу ( $H I=49,6 \pm 2,1$ при LV: 45,7-53,1), по индексу аттрагирующей способности $(A I=1,9 \pm 0,2)$ и по индексу линейной плотности колоса (ЛПК $=6,6 \pm 0,3$ ) (табл. 5). По остальным группам 6-го кластера распределялись генотипы, у которых уборочный индекс был на уровне 55,6-57,9, однако они не попали в лучшую (вторую) группу.

\section{4. Распределение сортов и селекционных линий пиеницы озимой по группам 6-го кластера} (селекционные индексы), 2009 г., СП-1

\begin{tabular}{|c|c|c|c|c|c|c|c|c|c|c|}
\hline \multicolumn{2}{|c|}{ Кластеры } & $\begin{array}{l}\text { Число } \\
\text { линий }\end{array}$ & УК & HI & AI & Mic & SPI & ЛПК & PI & $\mathbf{M x}$ \\
\hline \multirow{12}{*}{$\mathbf{K}_{6}$} & \multirow{2}{*}{ I } & 30 & $47,6 \pm 14,5$ & $48,6 \pm 2,1$ & $1,8 \pm 0,2$ & $3,1 \pm 0,4$ & $0,8 \pm 0,0$ & $5,7 \pm 0,4$ & $7,4 \pm 1,3$ & $2,8 \pm 0,4$ \\
\hline & & $\mathbf{L V}$ & $21,3-71,3$ & $42,7-54,2$ & $1,5-2,2$ & $2,5-4,0$ & $0,7-0,8$ & $4,4-6,2$ & $5,0-11,3$ & $2,3-3,4$ \\
\hline & \multirow{2}{*}{ II } & 18 & $44,8 \pm 15,1$ & $49,6 \pm 2,1$ & $1,9 \pm 0,2$ & $3,3 \pm 0,4$ & $0,8 \pm 0,0$ & $6,6 \pm 0,3$ & $8,2 \pm 1,0$ & $3,2 \pm 0,4$ \\
\hline & & LV & $13,8-71,9$ & $45,7-53,1$ & $1,6-2,3$ & $2,7-4,2$ & $0,7-0,8$ & $6,7-7,2$ & $6,7-10,5$ & $2,6-3,9$ \\
\hline & \multirow{2}{*}{ III } & 38 & $43,8 \pm 13,0$ & $51,7 \pm 2,3$ & $2,1 \pm 0,2$ & $3,2 \pm 0,4$ & $0,8 \pm 0,0$ & $6,1 \pm 0,3$ & $8,0 \pm 1,2$ & $3,0 \pm 0,4$ \\
\hline & & LV & $22,5-70,0$ & $46,4-55,5$ & $1,7-2,7$ & $2,3-4,0$ & $0,7-0,8$ & $5,7-6,5$ & $6,1-11,4$ & $2,4-3,8$ \\
\hline & \multirow{2}{*}{ IV } & 22 & $49,4 \pm 16,8$ & $49,4 \pm 2,7$ & $2,0 \pm 0,3$ & $3,0 \pm 0,4$ & $0,8 \pm 0,0$ & $5,2 \pm 0,3$ & $6,7 \pm 1,0$ & $2,5 \pm 0,4$ \\
\hline & & $\mathbf{L V}$ & $12,5-75$ & 43,4 & $1,5-2,6$ & $2,3-4,0$ & $0,7-0,8$ & $4,5-5,7$ & $5,1-9,7$ & $2,0-3,6$ \\
\hline & \multirow{2}{*}{ V } & 26 & $52,3 \pm 12,9$ & $54,3 \pm 2,5$ & $2,4 \pm 0,3$ & $3,5 \pm 0,5$ & $0,8 \pm 0,0$ & $6,5 \pm 0,4$ & $7,7 \pm 1,6$ & $2,9 \pm 0,5$ \\
\hline & & LV & $26,3-71,3$ & $50,4-57,9$ & $1,9-2,8$ & $2,8-4,2$ & $0,7-0,8$ & $6,0-7,3$ & $4,8-10,4$ & $2,3-3,7$ \\
\hline & \multirow{2}{*}{ VI } & 13 & $52,0 \pm 10,4$ & $54,3 \pm 2,5$ & $2,4 \pm 0,3$ & $3,5 \pm 0,5$ & $0,8 \pm 0,0$ & $6,5 \pm 0,4$ & $7,7 \pm 1,6$ & $2,9 \pm 0,5$ \\
\hline & & $\mathbf{L V}$ & $32,5-71,3$ & $50,4-57,9$ & $1,9-2,8$ & $2,8-4,2$ & $0,7-0,8$ & $6,0-7,3$ & $4,8-10,4$ & $2,3-3,7$ \\
\hline
\end{tabular}

5. Распределение сортов и селекционных линий пшеницы озимой по группам 6-го кластера (генеративные признаки), 2009 г., СП-2

\begin{tabular}{|c|c|c|c|c|c|c|c|c|}
\hline \multicolumn{2}{|c|}{ Кластеры } & $\begin{array}{l}\text { Число } \\
\text { линий }\end{array}$ & УК & $\mathrm{M}_{1}$ & $\mathrm{M}_{3}$ & ЧЗ & MT3 & КК \\
\hline \multirow{12}{*}{$\mathrm{K}_{6}$} & \multirow{2}{*}{ I } & 42 & $47,6 \pm 14,5$ & $2,3 \pm 0,2$ & $3,0 \pm 0,3$ & $53,5 \pm 4,8$ & $43,6 \pm 3,1$ & $19,0 \pm 1,3$ \\
\hline & & $\mathrm{LV}$ & $21,3-71,3$ & $1,9-2,8$ & $2,5-3,8$ & $43,2-67,5$ & $35,5-49,2$ & $15,8-22,0$ \\
\hline & \multirow{2}{*}{ II } & 33 & $44,8 \pm 15,1$ & $2,1 \pm 0,2$ & $2,8 \pm 0,2$ & $47,7 \pm 3,5$ & $43,8 \pm 2,5$ & $17,9 \pm 1,1$ \\
\hline & & LV & $13,8-71,9$ & $1,8-2,4$ & $2,3-3,1$ & $41,8-54,7$ & $38,8-49,9$ & $14,8-19,8$ \\
\hline & \multirow{2}{*}{ III } & 35 & $43,8 \pm 13,0$ & $2,2 \pm 0,2$ & $2,9 \pm 0,3$ & $52,5 \pm 4,1$ & $42,4 \pm 2,7$ & $18,8 \pm 0,9$ \\
\hline & & $\mathrm{LV}$ & $22,5-70,0$ & $1,8-2,5$ & $2,3-3,4$ & $42,9-60,0$ & $37,2-48,7$ & $17,0-20,6$ \\
\hline & \multirow{2}{*}{ IV } & 14 & $49,4 \pm 16,8$ & $2,4 \pm 0,2$ & $3,1 \pm 0,2$ & $53,1 \pm 5,5$ & $45,1 \pm 3,7$ & $19,5 \pm 1,1$ \\
\hline & & LV & $12,5-75$ & $2,0-2,7$ & $2,7-3,6$ & $44,5-62,8$ & $37,9-51,6$ & $17,6-22,0$ \\
\hline & \multirow{2}{*}{ V } & 25 & $52,3 \pm 12,9$ & $2,1 \pm 0,3$ & $2,7 \pm 0,3$ & $45,7 \pm 4,7$ & $45,1 \pm 3,6$ & $18,6 \pm 1,1$ \\
\hline & & LV & $26,3-71,3$ & $1,6-2,6$ & $2,1-3,2$ & $36,4-53,1$ & $36,8-50,5$ & $17,0-21,4$ \\
\hline & \multirow{2}{*}{ VI } & 18 & $52,0 \pm 10,4$ & $2,5 \pm 0,2$ & $3,2 \pm 0,3$ & $57,4 \pm 5,2$ & $44,0 \pm 3,2$ & $20,0 \pm 0,7$ \\
\hline & & LV & $32,5-71,3$ & $2,3-3,0$ & $2,8-3,9$ & $48,6-67,5$ & $36,9-47,9$ & $18,2-21,2$ \\
\hline
\end{tabular}


Анализ кластеров СП-2. Во втором сроке посева (СП-2) испытывалось 167 сортов и СЛ (табл. 5). По результатам кластерного анализа в СП-2 весь материал был распределен в 6 кластеров. Лучшей выделена шестая группа 6-го кластера, в которую вошли 18 сортов и СЛ. Урожайность в этой группе составила 52,0土10,4 ц/га с лимитом варьирования 32,5-71,3 ц/га (табл. 5).

Следует отметить, что урожайность в лучшей группе 6-го кластера в СП-2 была практически на таком же уровне $(52,0 \pm 10,4$ ц/га), как и в СП-1. Уровень формирования основных признаков генеративной части растения составлял (табл. 5): $\mathrm{M}_{1}=2,5 \pm 0,2 ; \mathrm{M}_{3}=3,2 \pm 0,3 ;$ ЧЗ $=57,4 \pm 5,2 ;$ МТЗ $=44,0 \pm 3,2$ и $\mathrm{KK}=20,0 \pm 0,7$, т.е. перечисленные признаки по уровню их формирования имели самое высокое значение по сравнению с другими группами кла- стеров. При этом и урожайность, и генеративные признаки в СП-1 и СП-2 находились практически на одном и том же уровне (табл. 1, 5). Это говорит о том, что в лучшей группе 6-го кластера сконцентрировались генотипы, которые обеспечивали практически одинаковый уровень формирования признаков, и величина их не зависела от сроков посева.

Анализ группирования вегетативных признаков в кластерном анализе показал, что их уровень формирования менялся, но незначительно. Отмечено снижение по лучшей группе 6-го кластера

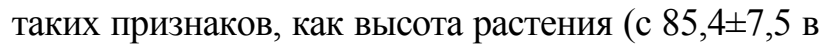
СП-1 до 79,3 $\pm 3,9$ в СП-2), длина колоса (с 9,4 $\pm 1,0$ в СП-1 до 8,4士0,6 в СП-2). Уменьшилось также значение массы стебля $\left(\mathrm{M}_{5}\right)$, а масса растения осталась на уровне СП-1 (табл. 3, 6).

\section{6. Распределение сортов и селекционных линий пшеницы озимой по группам 6-го кластера} (вегетативные признаки), 2009 г., СП-2

\begin{tabular}{|c|c|c|c|c|c|c|c|c|c|}
\hline \multicolumn{2}{|c|}{ Кластеры } & $\begin{array}{l}\text { Число } \\
\text { линий }\end{array}$ & УК & $\mathrm{H}$ & ДВМ & ДК & $\mathrm{M}_{2}$ & $\mathrm{M}_{5}$ & $\mathrm{M}_{4}$ \\
\hline \multirow{12}{*}{$\mathrm{K}_{6}$} & \multirow{2}{*}{ I } & 42 & $47,6 \pm 14,5$ & $75,9 \pm 5,0$ & $29,5 \pm 4,1$ & $8,6 \pm 0,8$ & $4,5 \pm 0,3$ & $1,5 \pm 0,1$ & $0,7 \pm 0,1$ \\
\hline & & $\mathrm{LV}$ & $21,3-71,3$ & $64,3-85,6$ & $18,9-36,2$ & $7,1-11,3$ & $3,8-5,2$ & $1,3-1,6$ & $0,5-1,0$ \\
\hline & \multirow{2}{*}{ II } & 33 & $44,8 \pm 15,1$ & $70,4 \pm 6,0$ & $28,2 \pm 3,6$ & $8,0 \pm 0,5$ & $3,9 \pm 0,3$ & $1,1 \pm 0,1$ & $0,7 \pm 0,1$ \\
\hline & & $\mathrm{LV}$ & $13,8-71,9$ & $57,8-84,9$ & $20,4-35,7$ & $7,2-9,0$ & $3,3-4,4$ & $1,0-1,3$ & $0,5-0,9$ \\
\hline & \multirow{2}{*}{ III } & 35 & $43,8 \pm 13,0$ & $69,6 \pm 5,1$ & $25,7 \pm 3,1$ & $7,7 \pm 0,5$ & $4,1 \pm 0,4$ & $1,2 \pm 0,1$ & $0,6 \pm 0,1$ \\
\hline & & LV & $22,5-70,0$ & $55,6-80,2$ & $17,5-31,7$ & $6,6-9,0$ & $3,2-4,6$ & $1,0-1,4$ & $0,5-0,9$ \\
\hline & \multirow{2}{*}{ IV } & 14 & $49,4 \pm 16,8$ & $87,2 \pm 6,4$ & $36,0 \pm 3,1$ & $9,7 \pm 0,9$ & $4,8 \pm 0,3$ & $1,7 \pm 0,1$ & $0,7 \pm 0,1$ \\
\hline & & $\mathrm{LV}$ & $12,5-75$ & $79,8-99,7$ & $30,1-40,2$ & $8,5-11,6$ & $4,4-5,5$ & $1,6-1,9$ & $0,6-0,9$ \\
\hline & \multirow{2}{*}{ V } & 25 & $52,3 \pm 12,9$ & $78,0 \pm 7,0$ & $30,8 \pm 4,7$ & $8,6 \pm 0,9$ & $4,1 \pm 0,4$ & $1,4 \pm 0,1$ & $0,7 \pm 0,1$ \\
\hline & & LV & $26,3-71,3$ & $62,9-92,4$ & $20,7-40,3$ & $7,0-10,4$ & $3,2-4,7$ & $1,1-1,5$ & $0,5-0,9$ \\
\hline & \multirow{2}{*}{ VI } & 18 & $52,0 \pm 10,4$ & $79,3 \pm 3,9$ & $30,8 \pm 3,7$ & $8,4 \pm 0,6$ & $4,9 \pm 0,4$ & $1,6 \pm 0,1$ & $0,7 \pm 0,1$ \\
\hline & & LV & $32,5-71,3$ & $71,7-84,9$ & $24,2-37,2$ & $7,4-9,3$ & $4,3-5,8$ & $1,5-2,0$ & $0,5-1,0$ \\
\hline
\end{tabular}

\section{7. Распределение сортов и селекционных линий пиеницы озимой по группам 6-го кластера} (селекционные индексы), 2009 z., СП-2

\begin{tabular}{|c|c|c|c|c|c|c|c|c|c|c|}
\hline \multicolumn{2}{|c|}{$\begin{array}{c}\text { Клас- } \\
\text { теры }\end{array}$} & $\begin{array}{l}\text { Число } \\
\text { линий }\end{array}$ & УК & HI & AI & Mic & SPI & ЛПК & PI & $\mathrm{Mx}$ \\
\hline \multirow{12}{*}{$\mathrm{K}_{6}$} & \multirow[b]{2}{*}{ I } & 42 & $47,6 \pm 14,5$ & $51,6 \pm 1,6$ & $2,1 \pm 0,2$ & $3,3 \pm 0,4$ & $0,8 \pm 0,0$ & $6,3 \pm 0,2$ & $8,0 \pm 1,2$ & $3,1 \pm 0,3$ \\
\hline & & LV & $21,3-71,3$ & $48,5-55,9$ & $1,8-2,6$ & $2,7-4,2$ & $0,7-0,8$ & $5,9-6,7$ & $6,1-12,0$ & $2,6-3,6$ \\
\hline & \multirow{2}{*}{ II } & 33 & $44,8 \pm 15,1$ & $53,6 \pm 2,1$ & $2,4 \pm 0,2$ & $3,2 \pm 0,4$ & $0,8 \pm 0,0$ & $5,9 \pm 0,3$ & $7,5 \pm 1,1$ & $3,0 \pm 0,4$ \\
\hline & & LV & $13,8-71,9$ & $49,0-56,8$ & $1,9-2,8$ & $2,4-4,2$ & $0,7-0,8$ & $5,4-6,5$ & $5,5-9,5$ & $2,3-3,7$ \\
\hline & \multirow{2}{*}{ III } & 35 & $43,8 \pm 13,0$ & $54,3 \pm 1,8$ & $2,3 \pm 0,3$ & $3,5 \pm 0,4$ & $0,8 \pm 0,0$ & $6,9 \pm 0,3$ & $8,8 \pm 1,3$ & $3,2 \pm 0,4$ \\
\hline & & LV & $22,5-70,0$ & $51,4-58,8$ & $1,9-2,9$ & $2,7-4,3$ & $0,7-0,8$ & $6,4-7,8$ & $5,9-11,1$ & $2,4-4,0$ \\
\hline & \multirow{2}{*}{ IV } & 14 & $49,4 \pm 16,8$ & $49,3 \pm 2,1$ & $1,8 \pm 0,2$ & $3,4 \pm 0,5$ & $0,8 \pm 0,0$ & $5,5 \pm 0,6$ & $6,7 \pm 1,0$ & $2,8 \pm 0,4$ \\
\hline & & LV & $12,5-75$ & $45,4-52,4$ & $1,4-2,0$ & $2,7-4,6$ & $0,7-0,8$ & $4,0-6,2$ & $5,2-8,5$ & $2,1-3,4$ \\
\hline & \multirow{2}{*}{ V } & 25 & $52,3 \pm 12,9$ & $50,4 \pm 2,2$ & $2,0 \pm 0,2$ & $3,1 \pm 0,4$ & $0,8 \pm 0,0$ & $5,3 \pm 0,3$ & $6,8 \pm 1,3$ & $2,7 \pm 0,4$ \\
\hline & & LV & $26,3-71,3$ & $45,2-55,3$ & $1,6-2,3$ & $2,4-4,0$ & $0,7-0,8$ & $4,7-5,8$ & $4,1-9,6$ & $1,8-3,4$ \\
\hline & \multirow{2}{*}{ VI } & 18 & $52,0 \pm 10,4$ & $51,6=$ & $2,0 \pm 0,1$ & $3,5 \pm 0,5$ & $0,8 \pm 0,0$ & $6,9 \pm 0,3$ & $8,3 \pm 1,0$ & $3,2 \pm 0,2$ \\
\hline & & $\mathrm{LV}$ & $32,5-71,3$ & $47,7-54,1$ & $1,7-2,3$ & $2,5-4,3$ & $0,7-0,8$ & $6,5-7,7$ & $6,9-9,8$ & $2,8-3,6$ \\
\hline
\end{tabular}


Уровень значений селекционных индексов (табл. 7) при группировке в СП-2 незначительно превышал их уровень в СП-1. Немного выше были значения в ЛГ 6-го кластера в СП-2 по уборочному индексу (НI), индексу аттракции (AI) и индексу линейной плотности колоса (ЛПК). Следует отметить, что значение индекса линейной плотности колоса как в СП-1, так и в СП-2 были одинаковыми и составляли $6,6 \pm 0,3-$ $6,9 \pm 0,3$.

По результатам кластерного анализа в 2009 году восемь сортов пшеницы озимой вошли в ЛГ 6-го кластера и в СП-1, и в СП-2. На дендрограммах (рис. 2, 3) они находятся на близких расстояниях друг от друга. Это сорта Перемога-2, Лелека, Nortonvesar-20, Кома, Носовская 2, Экономка, Колос Мироновщины, Степнянка. В дальнейшем они были вовлечены в гибридизацию, и в 2012 году получены гибриды 2-го поколения, по которым проведены отборы. В табл. 7 приведена характеристика этих сортов по основным количественным признакам в СП-1 и СП-2.

В 2009 году сложились самые благоприятные по сравнению с остальными годами исследований условия для роста и развития пшеницы озимой, и это способствовало тому, что была пре- доставлена уникальная возможность для реализации изучаемых генотипов по количественным признакам и формирования неплохого потенциала урожайности. Безусловно, если анализировать климатические условия периода вегетации (рис. 1), то осенний период 2008 года с достаточно высокой обеспеченностью влагой способствовал стартовому росту всходов озимых и высокому потенциалу урожайности. Сентябрь 2008 года (в период посева пшеницы озимой) имел на $36 \%$ влаги больше, чем в предыдущие годы, т. е. осадков было на 15,8 мм больше, чем по многолетней среднемесячной норме. Следовательно, влага в период посева определила весь ход онтогенеза пшеницы озимой, а также способствовала повышению потенциала урожайности и уровня реализации количественных признаков.

На дендрограммах (рис. 2, 3) показано распределение сортов пшеницы озимой в ЛГ 6-го кластера в 2009 году по СП-1 и СП-2 соответственно. Расстояния между сортами в этих группах варьировали в пределах одного уровня для обоих сроков посева. Это свидетельствует о том, что они действительно мало отличаются между собой по совокупности рассматриваемых признаков и селекционных индексов.

8. Характеристика сортов пиеницы озимой по основным хозяйственно полезным признакам, полученным по результатам кластерного анализа в 2009 2., СП-1, СП-2

\begin{tabular}{|c|c|c|c|c|c|c|c|c|c|c|c|}
\hline № каталога & \multicolumn{2}{|c|}{ Наименование сорта } & $\mathrm{y}$ & $\mathrm{M}_{1}$ & K3 & MT3 & $\mathrm{M}_{3}$ & $\mathrm{H}$ & $\mathrm{M}_{5}$ & $\mathrm{HI}$ & ЛПК \\
\hline \multirow{2}{*}{ UA0100757 } & \multirow{2}{*}{ Перемога-2 } & СП-1 & 37,5 & 3,2 & 62,8 & 50,3 & 4,3 & 97,3 & 2,6 & 45,7 & 6,9 \\
\hline & & СП-2 & 56,3 & 2,6 & 55,9 & 45,9 & 3,5 & 82,8 & 1,8 & 47,7 & 6,8 \\
\hline \multirow{2}{*}{ UA0103683 } & \multirow{2}{*}{ Лелека } & СП-1 & 50,0 & 2,8 & 62,0 & 44,8 & 3,7 & 83,7 & 1,8 & 51,1 & 6,3 \\
\hline & & СП-2 & 65,0 & 2,7 & 59,3 & 45,5 & 3,6 & 80,8 & 1,7 & 50,8 & 6,5 \\
\hline \multirow{2}{*}{ IU008437 } & \multirow{2}{*}{ Nortonvesar-20 } & СП-1 & 81,3 & 2,9 & 72,8 & 39,8 & 3,7 & 77,6 & 1,8 & 52,6 & 7,1 \\
\hline & & СП-2 & 71,3 & 2,6 & 67,5 & 38,7 & 3,3 & 76,6 & 1,6 & 54,1 & 7,7 \\
\hline \multirow{2}{*}{ UA0107466 } & \multirow{2}{*}{ Кома } & СП-1 & 85,0 & 2,4 & 65,7 & 37,1 & 3,3 & 78,9 & 1,9 & 47,2 & 6,3 \\
\hline & & СП-2 & 66,3 & 2,4 & 65,3 & 36,9 & 3,2 & 80,4 & 1,6 & 50,0 & 7,0 \\
\hline \multirow{2}{*}{ UA0104128 } & \multirow{2}{*}{ Носовская-2 } & СП-1 & 43,8 & 2,6 & 55,1 & 47,4 & 3,5 & 73,6 & 1,9 & 48,4 & 6,6 \\
\hline & & СП-2 & 47,5 & 2,4 & 54,1 & 44,9 & 3,4 & 71,7 & 1,6 & 48,4 & 6,8 \\
\hline \multirow{2}{*}{ UA0106530 } & \multirow{2}{*}{ Экономка } & СП-1 & 47,5 & 2,5 & 55,4 & 44,8 & 3,2 & 80,7 & 1,9 & 49,1 & 7,2 \\
\hline & & СП-2 & 51,3 & 2,4 & 55,0 & 43,8 & 3,2 & 81,4 & 1,7 & 49,1 & 6,8 \\
\hline \multirow{2}{*}{ UA0106532 } & \multirow{2}{*}{$\begin{array}{c}\text { Колос } \\
\text { Мироновщины }\end{array}$} & СП-1 & 56,3 & 2,7 & 62,5 & 42,9 & 3,4 & 82,2 & 1,7 & 52,3 & 6,4 \\
\hline & & СП-2 & 52,5 & 2,5 & 58,1 & 42,9 & 3,1 & 84,0 & 1,8 & 50,5 & 6,7 \\
\hline \multirow{2}{*}{ UA0106373 } & \multirow{2}{*}{ Степнянка } & СП-1 & 55,0 & 2,6 & 56,1 & 46,7 & 3,4 & 86,7 & 1,9 & 49,3 & 7,1 \\
\hline & & СП-2 & 50,0 & 2,4 & 51,5 & 47,2 & 3,0 & 76,4 & 1,5 & 53,1 & 6,8 \\
\hline
\end{tabular}




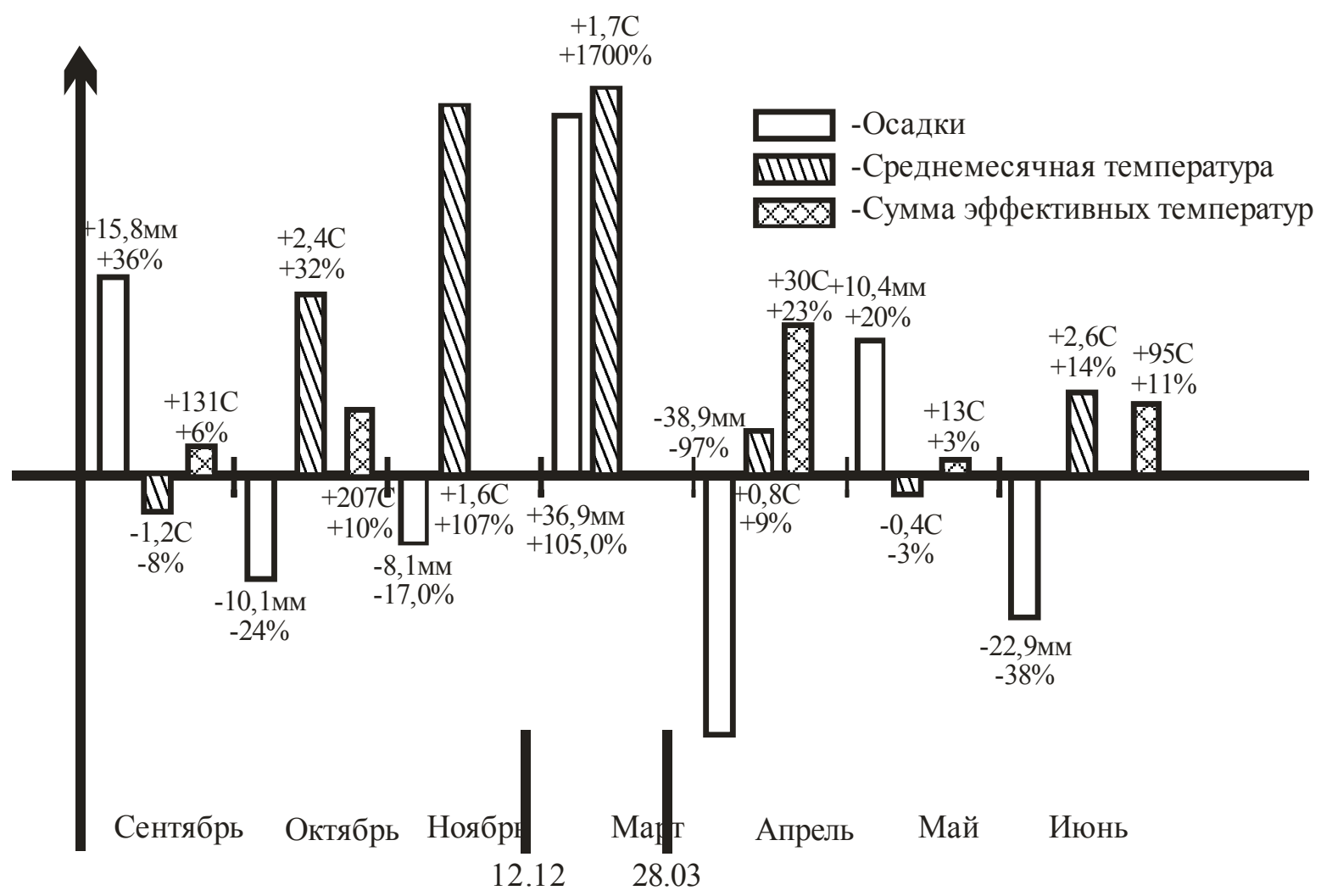

Рис. 1. Климатические условия вегетации пиеницы озимой 2008-2009 22.

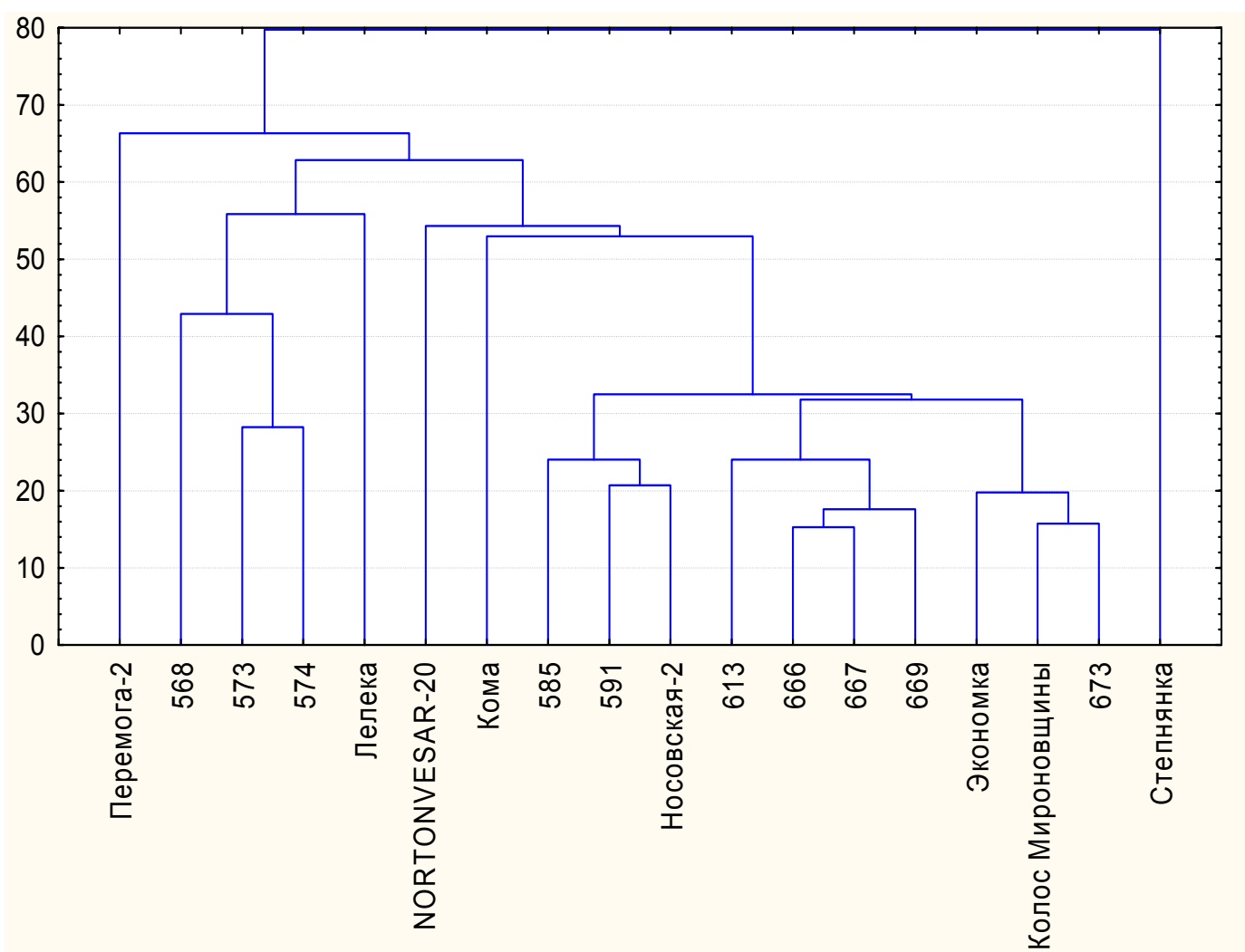

Рис. 2. Дендрограмма распределения сортов пшеницы озимой в ЛГ 6-го кластера, 2009 2., $C \Pi 1-1$ 


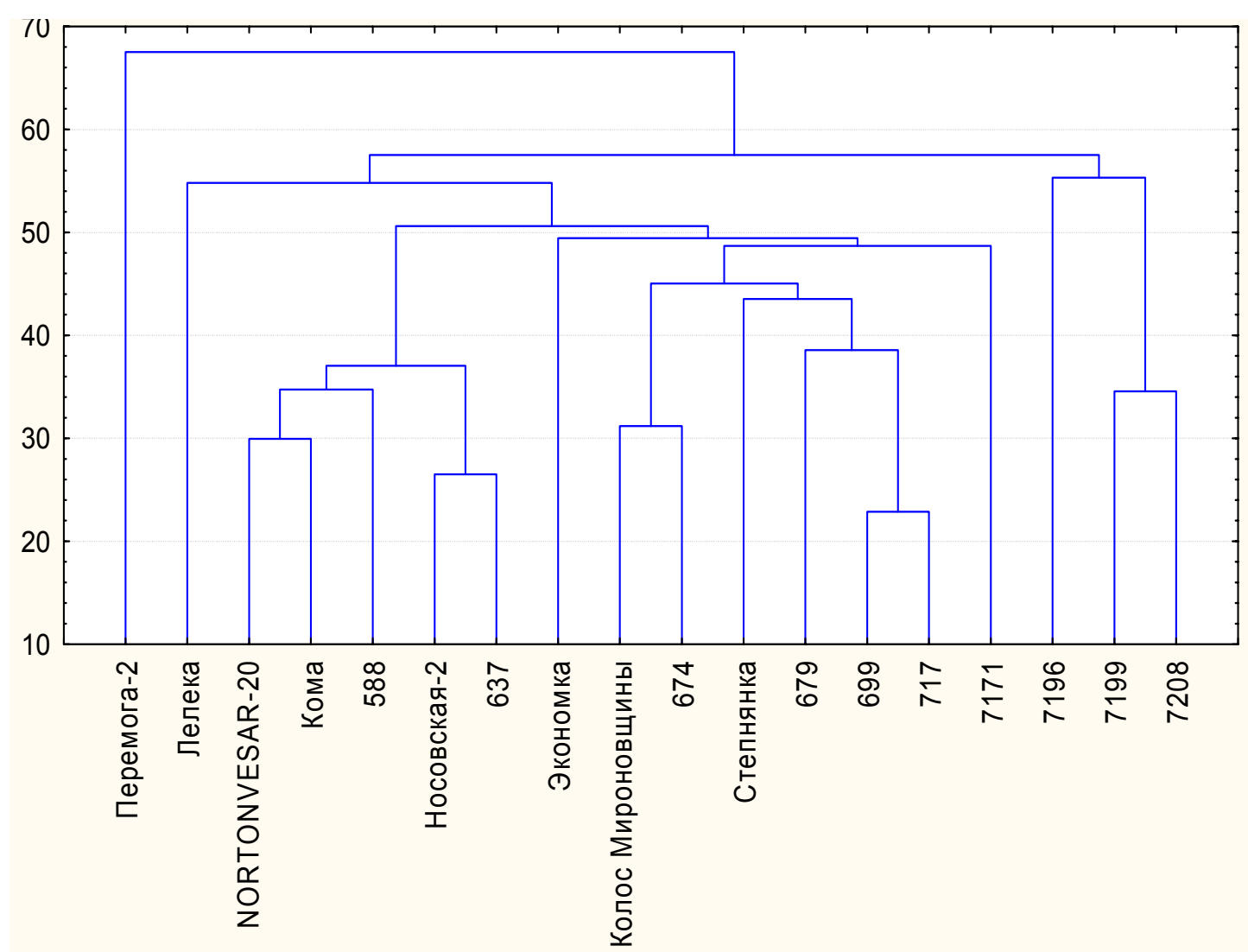

Рис. 3. Дендрограмма распределения сортов пщеницы озимой в ЛГ 6-го кластера, 2009 2., $\mathrm{CII-2}$

Выводы: 1. Идентификация сортов и селекционных линий пшеницы озимой с использованием кластерного анализа по двум срокам посева позволила выделить сорта, у которых наблюдалась четко выраженная сбалансированность количественных признаков и потенциала урожая. В лучших группах СП-1 и СП-2 концентрировались генотипы, обеспечившие практически одинаковый уровень формирования признаков, и величина их формирования не зависела от сроков посева.

2. Использование в кластерном анализе группирующих признаков $\left(\mathrm{M}_{5}\right.$ и ЛПК) позволяет идентифицировать по количественным признакам генотипы в группы с минимальным Эвкли-

\section{БИБЛИОГРАФИЯ}

1. Тищенко В. Н., Чекалин Н. М., Зюков М. Е. Использование кластерного анализа для идентификации и отбора высокопродуктивных генотипов озимой пшеницы на ранних этапах селекции. Фактори експериментальної еволюції організмів / Збірник наукових праць. - Т. 2. - К. : Аграрна наука, 2004. - С. 270-278.

2. Базалій B. В. Принципи адаптивної селекції пшениці озимої в зоні південного Степу / В. В. Базалій. - Херсон : Айлант, 2004. - 244 с. довым расстоянием между ними, а также оценивать сбалансированность сортов и селекционных линий по количественным признакам. Снижение определенного уровня формирования одного или нескольких признаков в сорте, а также в селекционной линии препятствует их включению в лучшую группу кластеров, даже если они имеют высокий уровень урожайности.

3. Использование кластерного анализа при идентификации генотипов приближает нас к созданию теоретической и практической модели сорта пшеницы озимой, идеальной по сбалансированности основных количественных признаков и урожайности.

3. Тищенко В. Н., Чекалин Н. М., Панченко П. М. Использование кластерного анализа для идентификации и отбора высокопродуктивных генотипов озимой пшеницы в процессе селекции // Генетика и биотехнология XXI века. Фундаментальные и прикладные аспекты : материалы Международной науч. конф., 3-6 дек. 2008 г., Минск / редкол. : Н. П. Максимова (отв. ред.) [и др.]. Минск : Изд. центр БГУ, 2008. - 364 с. 